Housing Studies, Vol. 15, No. 4, 613-638, 2000

\title{
Housing Histories and Homeless Careers: A Biographical Approach
}

\section{JON MAY}

Department of Geography, Queen Mary and Westfield College, University of London, London, UK

[Paper first received October 1998; in final form June 1999]

ABSTRACT Though distinctions are commonly drawn between the long-term and more recently homeless, our understanding as to the nature and shape of what Randall refers to as 'homeless careers' is limited as are our understandings of the dynamics driving those careers. This is because studies of homelessness have seldom incorporated a longitudinal dimension or have worked with only a simplistic and incomplete picture of homeless people's housing histories. The paper argues for the adoption of a biographical approach in studies of homelessness and reports on the first complete set of accommodation biographies constructed with single homeless hostel users. It is shown that, rather than fitting a description of either the long-term or more recently homeless or following a progressive 'drift' into homelessness, the majority of men interviewed had in fact experienced numerous homeless episodes in the past but with each of these episodes being of relatively limited duration and separated by much longer periods in (their own) accommodation. Examining the nature of that accommodation, it is shown that the housing careers of these men had been almost entirely dominated by the use of poor quality and often insecure private rented bedsits and flats whilst almost all had simultaneously been either long-term or permanently unemployed. With few additional 'vulnerabilities' to help account for their frequent returns to homelessness the paper challenges a conventional 'political model' of single homelessness to explain these men's homeless careers in relation to their position of multiple structural disadvantage. The paper contrasts these biographies with the biographies of those who were either visibly homeless for the first time or who better fitted a description of the truly long-term homeless and concludes by outlining the ways in which a biographical approach might further our understanding of single homelessness more broadly and enable the formulation of more appropriate responses to the problems of homelessness.

\section{Introduction}

Though by no means as yet accepted by all, a new orthodoxy is slowly emerging amongst those seeking to explain single homelessness. Identified first by Brandon et al. (1980) and subsequently developed by Liddiard (1992) within a 'political model' homelessness is seen as neither simply a housing nor a welfare issue, caused by neither only structural nor individual factors. Instead, homelessness is explained with reference to the manner in which changing structural conditions impact most severely upon particular groups, either be- 
cause of a simple position of structural disadvantage or (more usually) because of some further vulnerability that renders a person especially ill equipped to cope with those changes (Pleace et al., 1997).

In support of such an explanation, advocates of the political model point to the manner in which changes over the past 15 years or so in the nature of and relationships between housing and labour markets, demographic and welfare regimes have mirrored an increase in single homelessness amongst precisely those groups most vulnerable to these changes (Carlen, 1996). At the same time, rather than simply discount the role that individual vulnerabilities play in the homelessness dynamic, such vulnerabilities are presented as a contributory factor, useful for explaining why one person in an otherwise similar position is more likely to become homeless than another. Thus, noting the increasing proportion of women, the unemployed and those under the age of 25 in the single homeless population, for example, the same studies also point to the continued over-representation within that population of those with a history of institutional care, problems of mental or physical health, drug addiction or alcohol dependency (Anderson et al., 1993).

The advantages of such a model are clear. Whilst offering a convincing explanation of the factors shaping recent changes in the single homeless population, it is also useful to the formulation of any response to the problems of single homelessness with advocates of the political model tending to point to variations of a 'housing plus' solution. Hence it is argued that although the more general need is for an increased supply of secure and affordable housing, any response to single homelessness must also take account of the need for increased training and employment opportunities and recognise that a significant proportion of single homeless people will require additional support once placed in housing if they are to retain that accommodation (Neale, 1997).

Despite its growing acceptance, however, there remain a number of problems with the manner in which studies adopting this model have proceeded. Not least, surprisingly few have deployed the kinds of methods that enable it to be unpacked in any detail. Rather, most continue to rely upon the kind of quantitative approaches-specifically the questionnaire survey-that though demonstrating a clear 'fit' between a changing single homeless population and the broader processes driving an increase in single homelessness in recent years, cannot trace the different ways in which people negotiate these broader structural changes and with differing outcomes (Akiyu, 1992). As a result, too often it can appear as though a person's homelessness is an inevitable consequence of either their structural position (with the specifics of how that position 'translates' in to homelessness left largely unexplored) or a specific set of vulnerabilities, with the role of the latter perhaps over-emphasised in explanations of why some people are more likely than others to become or remain homeless (Jones, 1993).

In part as a result of these limitations, a number of more recent studies have begun to adopt alternative methodologies including semi-structured interviews, ethnography and participant observation with the aim of framing "the issue of homelessness in terms of an agent, contending with a set of social problems, rather than as an individual entrapped in history ... [and with an understanding of people] as active participants in the experience, negotiation and (re)creation of their personal and social histories" (Tomas \& Dittmar, 1995, p. 497). The turn to a qualitative approach has been far more successful in developing our 
understanding of the complex interplay of factors that can lead to a person becoming homeless. It has also helped explore the experiences of homelessness and the different ways in which people negotiate that experience (Watson \& Austerberry, 1986).

But these studies too are ill-suited to moving beyond an explanation of why people become homeless to a fuller understanding of the nature and dynamics of what Randall (1988) refers to as 'homeless careers'-moving beyond questions as to why a person may become homeless towards a better understanding of the length of time that different people remain homeless or the factors shaping a person's movements in and out of homelessness over time (Farr et al., 1986; Rossi, 1989). This is, most obviously, because irrespective of the methods used most studies of homelessness are conducted only at the point at which a person presents as 'visibly' homeless and concentrate most fully upon their experiences at that time or their circumstances immediately prior to that time such that "the life stories of homeless people are typically devalued, shunted aside or unconsciously limited" (Daly, 1996, p. 10).

Drawing upon a biographical approach only rarely used in studies of homelessness but increasingly common in other fields, the paper demonstrates how a recovery of those stories essential if studies of homelessness are not to continue to deny homeless people an identity and agency beyond only their position as 'homeless' — can further our understanding of single homelessness in important ways and of homeless careers in particular (Hutson \& Liddiard, 1991; Jarvis, 1997; Jones \& Stevens, 1993; Murie \& Jeffers, 1987).

Analysing the first complete set of accommodation biographies constructed with single homeless people, the paper suggests that previous studies have misrepresented the basic nature and shape of homeless careers and have failed to identify the key dynamics driving those careers. Rather than progressive, as previously suggested, it is shown that for the majority of single homeless people the experience of homelessness is neither singular nor long term but episodic, with each homeless episode interspersed with often extended periods in their own accommodation and with no increase in either the frequency or duration of homeless episodes over time.

Examining the processes driving those careers it is further suggested that previous studies have over-emphasised the role that individual vulnerabilities play in the homeless dynamic. With few of the episodically homeless displaying such vulnerabilities, that dynamic is better explained with reference to the broader housing and employment histories described by those whose lives have been almost entirely dominated by the use of low quality often insecure private rented housing and long-term unemployment. The paper does not deny the importance that further problems of alcohol or drug dependency, mental or physical health play in the lives of some homeless people, and the truly long-term homeless in particular. But it challenges conventional understandings of homelessness that would explain the experience of a significant proportion of homeless people as one emerging out of a further set of problems that position some as 'especially vulnerable' to broader structural changes and thus more liable to become homeless than others in otherwise similar positions. It suggests instead that for the majority of single homeless people their homelessness may be explained by simple reference to a position of multiple structural disadvantage: the coming together of a legislative framework that restricts poorer single people's access to more secure forms of housing; a housing market that restricts 
poorer people's access to accommodation found almost exclusively at the lower end of the private rented sector; and long-term unemployment.

Exploring the manner by which people negotiate that position, the paper champions the use of a more developed biographical method hinging around the construction of 'triple' biographies (Halfacree \& Boyle, 1993). Such a method is capable of further unpacking the manner by which a person's experiences in different arenas 'come together' to place them in a position of multiple disadvantage. It also re-inserts the question of agency within a proper consideration of the structures of opportunity and constraint that frame a person's action at any one time. Moving beyond this, as it captures something of the sequential nature of social action, a biographical approach may also help explain why those who become homeless may remain homeless or why those who have been homeless once frequently become homeless again (and again) at some later stage of their housing career (Adams, 1990; Jarvis, 1997).

\section{Understanding Homeless Careers}

The most obvious factor constraining a fuller understanding of homeless careers is the difficulty in establishing any kind of longitudinal dimension to studies of homelessness (Sosin et al., 1990). Though such problems are not unique to those working with homeless people, the rapid movement through accommodation of different kinds and the high degree of geographical mobility that sometimes accompanies such moves has meant that remaining in contact with single homeless people so as to establish this longitudinal dimension has proved especially problematic (Conover et al., 1997). In light of such difficulties those wishing to trace the development of homeless careers have more usually turned to some kind of biographical approach in an attempt to reconstruct a person's homeless history up until and including their current homeless episode.

But in the most part such histories have remained extremely schematictypically consisting of little more than an indication of whether a person has used night shelter or hostel accommodation prior to their current homeless episode, of the number of times a person has slept rough and for how long or the details of their last few addresses (Anderson et al., 1993; Jones \& Stevens, 1993). Though such information allows for crude distinctions to be drawn between the first time and previously homeless, it gives little indication of how long a person has been homeless, in comparison to time in accommodation, for example of the 'shape' of their homeless career and its relationship to their broader housing history-the timing and duration of individual homeless episodes and intervening patterns of accommodation use; or of the detailed relationships between homelessness and a person's experiences in other arenas, so as to allow for a fuller consideration of the relationships between homelessness and unemployment, for example. Nor does it allow for a consideration of the ways in which different forms of homelessness (whether 'visible' or 'hidden') relate to each other and as is necessary if we are to deploy a more sophisticated understanding of homelessness as part of a broader continuum of housing need rather than an absolute state (Watson \& Austerberry, 1986).

Yet such issues are clearly of some importance. Not least, the health and welfare needs of people who have been 'visibly' homeless for a long time (staying in night shelters or hostels, in bed and breakfast accommodation or 
sleeping rough) and of those with a prolonged history of rough sleeping in particular have been found to be especially acute (Bines, 1994). Likewise, just as it is becoming clear that the accommodation and other needs of homeless people differ, as does the kind of housing or assistance desired by homeless people themselves, so too it may be that different kinds of homeless career require different kinds of intervention (Vincent et al., 1995). Finally, whilst both popular and academic accounts continue to construct homelessness as progressive, where a period of street homelessness can make employment and thus accommodation ever harder to find, it is not at all clear how such processes operate over the longer term or whether, and if so how, the circumstances, experiences and characteristics of those who continue to be homeless for some time after first becoming homeless differ from those whose homelessness is of far shorter duration (on the 'vicious circle' of street homelessness see Carlen, 1996).

The most detailed housing and homeless histories so far constructed are those developed by Sosin et al. (1990) and Hutson \& Liddiard (1991). In the first of these studies, conducted in the US, an attempt was made to trace the accommodation biographies of some 450 single homeless men over a six-month period (Sosin et al., 1990). Using the data provided by this study Pavialin et al. (1993) set out to answer three key questions concerning the nature of homeless careers, namely: (1) whether homelessness should be considered a sudden and singular accommodation crisis; (2) whether it should instead be defined as a long term and relatively permanent state; or (3) whether once homeless a person's homeless career tends to develop by means of ever more frequent homeless episodes of increasing duration towards a point at which it can be considered permanent. In contrast, Hutson \& Liddiard (1991) worked with the accommodation biographies of 115 young people aged between 16 and 25, including both those visibly homeless at the time of the study and those who had been homeless at some point in the past.

Although drawing upon very different explanatory frameworks and working with different populations, both studies drew similar conclusions regarding the nature and 'shape' of homeless careers. Thus Pavialin et al. conclude that although such careers rarely develop to the point at which a person's homelessness can be considered permanent-in-so-far as all the men interviewed had spent some time within the six-month period in accommodation either of their own or of friends and relatives, rather than night shelters, hostels and other accommodation provided specifically for homeless people-they are clearly progressive; with a tendency amongst even the more recently homeless for a first homeless episode to be followed by subsequent episodes of both increasing frequency and duration (Pavialin et al., 1993).

For Hutson and Liddiard (1991) and though noting that the careers of some respondents were 'interrupted' before running their full course, the accommodation biographies of young people who became homeless are described as typically moving through a series of distinct stages. In the first of these, whilst some became homeless immediately upon leaving home, most tended to use a wide variety of accommodation including friends and relatives, private rented bedsits and flats and youth projects. At the next stage, though many returned home after an unsuccessful attempt at independent living, the use of both friends and especially relatives declined as more people moved in to their own accommodation, most often in the private rented sector. In the final stage, independent accommodation all but ceased and, if not sleeping rough, in times 
of accommodation crisis people turned either to friends (but rarely relatives) or to traditional hostels for the homeless, a feature of only these latter stages. Thus, as in the study by Pavialin et al. (1993) homelessness is understood as progressive with Hutson \& Liddiard suggesting that where previous studies have drawn distinctions between the long-term and more recently homeless, what such studies may in fact be finding is people presenting at different stages in a more general trajectory towards street homelessness (Hutson \& Liddiard, 1991, 1994).

Though useful, both sets of studies have a number of important limitations. Most obviously, whilst the definition of homelessness used by Pavialin et al. (1993) to define the onset and exit from a homeless episode is ambiguous, the study's timescale is such that it can tell us little that is meaningful about the place of people's homeless careers within their broader accommodation biographies. With a timescale of only six months, and an exit from homelessness defined as only 14 nights, it is quite possible that rather than tracing a series of 'homeless careers' the study in fact reveals only the rapid movement of people through accommodation within what might more reasonably be viewed as a single homeless episode. Further, neither this nor subsequent studies that have used the same data can usefully explain the dynamics that drive these 'careers'. Caught within an explanatory framework that seeks to explain homelessness by means of individual pathology, Pavialin et al.'s. $(1993,1996)$ studies consider none of the surrounding structural features that clearly shape a person's ability to find and to retain accommodation.

Whilst drawing upon a more sophisticated explanatory framework, Hutson \& Liddiard's study considers only young people's housing careers and the biographies they construct contain no record of the duration of each accommodation event such that it is difficult to place a person's homelessness in the context of time spent in their own accommodation. More significantly, difficulties emerge in interpreting the dynamics driving those biographies. For example, although reporting that some 70 per cent of the young people interviewed had originally left home following serious family conflict which had in turn constrained the accommodation options of many in times of future housing need, it is not clear given the high levels of such conflict across the sample population as a whole, why only some of the young people interviewed should go on to the final stages of street homelessness (Hutson \& Liddiard, 1991). More generally, though the different factors shaping each person's biography are clearly outlined in a series of careful case studies, at no point is there an attempt to aggregate those factors such that it becomes possible to see whether the circumstances of those whose homeless career developed through each of the stages identified differed, or in what ways, from those able to avoid such a trajectory.

\section{Developing a Biographical Approach}

It was in part to move beyond such limitations that the study reported here was conducted. The aim was to construct a more detailed set of accommodation biographies-including every accommodation and rough sleeping event, and the duration of those events, since a person had first left home-and for a wider range of single homeless people than previously attempted. Further, rather than tracing only a person's housing and homeless history the aim was to attempt the construction of a series of 'triple' biographies, outlining any changes in a 
person's personal and employment circumstances along the same timeline so as to better contextualise any changes in accommodation circumstance and to be able to relate those changes to that person's experience in other arenas (Forrest \& Murie, 1991; Maya \& Tuma, 1987).

The construction of so detailed a set of biographies-capable of capturing accommodation events ranging in duration from a single night to several years - is by no means easy or straightforward and not least because the detailed ordering of events necessary for such biographies requires considerable abilities of recall. The ability to recall events to this level of detail and sequentially has been found to differ according to circumstance, dependent in part upon a person having an established temporal frame in which to set those events (Tonkin, 1995). Such a frame is commonly provided by a person's employment history such that the long-term unemployed, for example, find such narratives difficult (Barclay, 1986). Likewise, people often find it difficult to accurately recall especially traumatic events, or may at least be unwilling to do so until such point that a relationship of trust has been established with the person for whom one is undertaking the act of recall (Rubin, 1986). Given that homeless people have also often been unemployed for long periods of time, may lack other obvious markers by which to frame events (not least, a stable accommodation biography), and that the events being recalled-becoming homeless-may also be traumatic it is clear that establishing detailed biographies from which to reconstruct a person's homeless career may be difficult, even in those cases where recall is not hampered by more obvious problems of memory loss or disruption experienced by those with a history of drug or alcohol dependency or mental health problems (Evert \& Oscarberman, 1995; Jones, 1993; Vincent et al., 1995).

The study was based in a resort town on the south coast of England. With a population of approximately 250000 , the town has previously been identified as having both unusually high levels of single homelessness and of rough sleeping in particular relative to its size, and a high level of provision for the homeless in the form of a well co-ordinated local network of advice agencies, soup kitchens, day centres and supported housing schemes (Shaw, 1998). The town also has two direct access hostels, providing some 82 beds between them, and a dormitory-style night shelter with space for a further 12 men. Following the recent closure of a supported housing scheme for vulnerable young women, accommodation for homeless women is, however, far less developed to the extent indeed that only three beds are specifically set aside for women in one of the direct access projects with the other two only accepting men.

Because of this, and because homeless women also tend to make up a far smaller proportion of those using the town's day centres and soup runs, the decision was made to concentrate the study upon the homeless careers of single homeless men. At the same time, having conducted a pilot study with users of a local day centre, a decision was also made to base the study at the night shelter and the smaller of the two direct access hostels. Whilst it is recognised that this restricts the study's findings to those currently using night shelter and hostel accommodation (rather than bed and breakfast hotels, sleeping rough or in other forms of insecure and temporary housing) such restrictions also have a number of advantages. First, by interviewing all but five of those resident in two of the direct access schemes within the same two-week period (some 43 people) the biographies may be considered broadly representative of 
the wider single homeless direct access hostel population. Second, and more important perhaps, working with a relatively static population gave space for the development of the kinds of relationships necessary to construct biographies at the required level of detail.

The ways in which these relationships developed differed considerably according to the person being interviewed and the atmosphere and dynamics of the two schemes. All developed over time, with one advantage of working at the night shelter being that the author had already worked there as a volunteer warden for some 18 months prior to the study and such that strong relationships had already formed with a number of men using the scheme. Building upon these relationships, the biographical interviews only proceeded once a person had either asked to be interviewed or when it was felt a relationship of sufficient trust had developed to conduct the interview-such that although interviewing only those resident in either scheme at the same time, a number of the interviews themselves were conducted outside of this two-week period. The most obvious result of this time spent establishing strong relationships with each of the respondents was that by the time of interview people began to move beyond the kind of standard narratives that had often characterised earlier informal discussions and were able to talk in some detail about events (the break up of a relationship or the loss of their home, for example) that had often been traumatic.

The recounting of a standardised narrative is a common feature of life history work and such narratives may in themselves give important clues as to the internal 'rules' by which different people make sense of their lives (Chamberlayne \& King, 1993). Yet where such narratives work to obscure a set of basic biographical details essential to a study they may also be problematic. The omission of certain kinds of information or events (a person's drug habits or the manner in which they left employment or accommodation) is perhaps especially common in life history work undertaken with homeless people and not least as people may in the past have been punished for revealing such information; during resettlement work or when making a benefit claim, for example. The case of 'Peter' illustrates this process well (all names have been changed). Previously denied a place in a supported housing scheme having declared his drug use, the contributory role of that drug use to the break up of his marriage and thus to the loss of both his marital home and subsequent accommodation only became apparent having already talked with Peter on numerous occasions. It was only after these initial discussions that Peter was 'formally' interviewed.

Though constructed around a formal interview guide, the interviews themselves were relatively free-flowing giving people the time to talk around their biographies so as to capture the multiplicity of factors shaping their actions at particular points in time and explore the detailed timing of events in different parts of the biography (for example, those relating to housing or employment change) (Akiyu, 1992; Halfacree \& Boyle, 1993). Likewise, although it was explained that the resultant biographies had to be both accurate and sequential, people were encouraged to explore their biography in the way they found easiest, with some starting at the point they left home and working forwards and others from their current situation and working back in time (Campanelli \& Thomas, 1994; Martin \& Roberts, 1984).

Rather than taped, the details of each person's biography were recorded on a series of pre-prepared interview guides detailing: 
- the type and duration of each place of accommodation (with banded information in days, weeks and months up to five years and actual time, in years, for longer periods);

- the manner by which they had found that accommodation;

- people, if any, with whom they shared;

- the form, and their responsibility for, rent or other payments;

- security of tenure;

- details of income, benefits and employment;

- reasons for leaving that accommodation.

A second sheet recorded details concerning any periods of rough sleeping, including the length of each continuous episode and details of attempts, if any, to access accommodation at that time and the factors relating to the inability to do so.

As a person talked, a new sheet was completed by the interviewer for each place of accommodation or episode of rough sleeping recalled with these combining to form a continuous triple biography relating to changes in accommodation, employment and personal circumstances with the whole recorded along a single timeline. Rather than asking people to date their biographies, the timeline itself was constructed by combining the duration of each accommodation or rough sleeping event to give a total time in days since first leaving home. At the end of each interview, and following a break, the interview was re-convened. Here, the author would draw a crudely annotated timeline marking each point of accommodation and, working from the completed interview sheets, recount the person's biography to the interviewee. At this stage though it was not uncommon to find that respondents had omitted a number of accommodation events from their account, more usually those of shorter duration, these could simply be inserted in their correct place in the chronology such that a full biography was established.

Finally, a series of tape-recorded interviews were also conducted with a small number of the original respondents (nine) after the construction of their biographies. The aim of these was to expand upon people's own interpretations of their histories, to fill-in details concerning individual events (for example, the ways in which a person coped when sleeping rough or the reasons behind their moves) and to give people the opportunity to explore their own experiences of homelessness, including their understandings of 'home' and 'homelessness' (Tomas \& Dittmar, 1995; Watson \& Austerberry, 1986) ${ }^{1}$.

\section{Housing and Homeless Careers Reconsidered}

Because the biographies reported here were constructed with people currently using night shelter and hostel accommodation, they cannot necessarily be compared to the biographies of other single homeless people. As has been demonstrated by others, whilst hostel-based studies tend towards an under-representation of those with a prolonged history of rough sleeping so too they will inevitably contain a disproportionate number of the long-term homeless and those with a long history of hostel use in particular (Jones \& Stevens, 1993). Where previous studies conducted with women have traced quite different patterns of homelessness to those shown here, and quite different dynamics underlying their homelessness, nor should the biographies be understood as 
necessarily representative of the experiences of single homeless women (Tomas \& Dittmar, 1995; Watson \& Austerberry, 1986).

At the same time, although the sample population itself is quite small, the level of detail provided by the biographies means that taking the respondents as a whole it is possible to analyse over 100 distinct homeless episodes such that the sample may be regarded as equating to much larger surveys in which details are recorded regarding only a person's current homeless episode (Randall, 1992 $)^{2}$.

So too a consideration of the basic characteristics of the study's population demonstrates those characteristics to be broadly in line with previous and much larger surveys of hostel users. For example, of the 43 people interviewed (all but one of whom was white) 12 were aged 25 or under, with an average age of 31 . Only one person was working at the time of interview; 16 reported some kind of drug or alcohol dependency, 32 had at some time slept rough (six of whom had done so for prolonged periods) and 31 had used hostels at some point in the past (Anderson et al., 1993).

On its own, however, such information tells us little that is useful to an understanding of the dynamics of homelessness and may even be misleading. For example, asking only about previous hostel use or experiences of rough sleeping can give little indication of how long a person has been homeless or the 'shape' of their homeless career. Thus, whilst 11 of the respondents were (visibly) homeless for the first time, for most this homeless episode was already of some duration, meaning that many had slept rough on numerous occasions or had already used a number of hostels. Moreover, though of the other 32 respondents all had experienced numerous homeless episodes, by no means all fitted any easy or simplistic definition of the 'long-term' or 'chronically' homeless (Whynes, 1991).

Rather, looking in more detail at the housing and homeless careers of these other respondents revealed marked differences in the nature of both people's general homeless 'trajectories' and their experience of individual homeless episodes. For some, homelessness clearly formed the dominant feature of their housing careers, accounting for some 36 per cent of their time since first leaving home and with individual homeless episodes typically in the range of some 18 months. In contrast, for a much larger group not only was the total time homeless relative to time since first leaving home less ( 9 per cent) so too each homeless episode was typically of much shorter duration, averaging at just over three months each across the group as a whole.

Such differences complicate the rather simplistic models of long-term homelessness identified by Pavialin et al. (1993) and Hutson \& Liddiard (1991). Most obviously, rather than representative of those yet to move through the full trajectory into long-term homelessness, it may be that the homeless careers of the more recently homeless in fact differ in important ways from those of the long-term homeless and that lying between both is a further group for whom homelessness is neither a singular experience nor a truly long term one but who might fit better within some notion of the 'episodically' homeless. The remaining part of the paper explores the experience of each of these groups in turn.

\section{The Long-term Homeless}

Where the approach outlined above allows for a detailed examination of both 
the nature and dynamics of homeless careers, it becomes clear that even amongst the truly long-term homeless such careers rarely develop in the ways identified in previous studies. Thus, looking at the biographies of each of the eight men for whom homelessness had been a relatively long-term experience revealed neither that pattern of 'drift' identified by Pavialin et al. (1993)—with homeless episodes of increasing frequency and duration-or any clear movement through a biography marked by different types of accommodation as identified by Hutson \& Liddiard (1991) (Figure 1).

Instead for some, like Russell for example, homelessness had been an almost immediate and permanent experience following initial difficulties in retaining his own accommodation and an unsuccessful return home. For others, like Rob or Alan, prolonged periods of rough sleeping, some lasting for two years or more, had been interspersed with equally long stays in their own accommodation (whether in the private rented or social housing sectors) that had interrupted but by no means arrested a return to street homelessness. Still others, like Gary or Nick, had never had their own accommodation but had instead moved continuously between periods in hostels or on the street and spells with friends and relatives. Whilst for Bill a long period 'on the road' came relatively late in his housing career after a life at sea with the merchant navy and which included shore leaves in seaman's missions and hostels all around the British Isles.

More importantly, drawing upon information emerging out of a triple biography it is possible to identify a number of features that draw these otherwise unique histories together. Most obviously, and other than the extensive periods each had been homeless, each of these men shared a history of long-term unemployment. Indeed, although the group ranged in age from 21 to 49 years of age, only two of the men had ever worked and for them their homelessness had begun at the end of their working lives. Likewise, all but one had serious and sometimes multiple vulnerabilities that had made finding and retaining independent accommodation extremely difficult. Russell, for example, suffered from severe epilepsy (often mistaken for drug withdrawal when he fitted on the street) from which he had almost died when he last tried to live on his own. Gary and Chris were heroin addicts, starting for Gary before he left home and resulting in a number of spells in prison for offences related to attempts to find money for his habit, and for Chris when in prison and since resulting in several stays in hospital from where he had be discharged without an address to go to and had subsequently ended up sleeping rough. Both Alan and Don were alcoholics, with their drinking starting at an early age after especially traumatic childhoods. Whilst Don's alcoholism had led first to the separation from his wife and later to a series of evictions from private rented flats, supported housing schemes and hostels, Alan's had led both to his first long-term relationshipwith a woman he met on the streets who also drank and with whom he was able to gain a local authority flat-and to the break-up of that relationship and a return to the streets.

Given these characteristics it may therefore appear that the men in this first group seem to fit with an understanding of (long-term) homelessness as both a housing and a 'welfare' issue (Neale, 1997). Certainly, all but one of the men interviewed considered themselves incapable of independent living. But the very different experiences relayed by each also suggest that any response to these men's homelessness requires a move beyond a simple 'welfare and 


\begin{tabular}{lrrrrrrrrrr}
\hline Nick (age 21) & $\mathbf{2 5 8}$ & 18 & $\mathbf{1 8}$ & 547 & $\mathbf{2 5 8}$ & 547 & $\mathbf{4 1 8}$ & & & \\
Gary (23) & $\mathbf{2 5 8}$ & 366 & $\mathbf{1 3 6}$ & 136 & $\mathbf{3 0 3}$ & 457 & $\mathbf{9 1}$ & & & \\
Russell (26) & 303 & $\mathbf{2 4 4 4}$ & 547 & $\mathbf{5 7 4}$ & & & & & \\
John (29) & 3241 & $\mathbf{4 5}$ & 136 & $\mathbf{1 8 1}$ & 95 & $\mathbf{3 3 4}$ & 136 & $\mathbf{6 2 3}$ & \\
Rob (31) & 850 & $\mathbf{1 8 2}$ & 1488 & $\mathbf{5 4 7}$ & 930 & $\mathbf{5 4 7}$ & 837 & $\mathbf{2 0 2}$ & & \\
Alan (34) & 5 & $\mathbf{2 5 8}$ & 552 & $\mathbf{2 4 4 4}$ & 1081 & $\mathbf{1 8 2}$ & 18 & $\mathbf{5 9 0}$ & \\
Don (49) & 2302 & $\mathbf{1 0}$ & 3662 & $\mathbf{7 6}$ & 141 & $\mathbf{4 5}$ & 2417 & $\mathbf{3 2 3}$ & 45 & $\mathbf{2 0 8 2}$ \\
Bill (49) & 7421 & $\mathbf{1 9 8 1}$ & 45 & $\mathbf{6 1 6}$ & 685 & $\mathbf{1}$ & & & & \\
\end{tabular}

\section{Explanation:}

Timeline begins with first accommodation or homeless episode on first leaving home.

Each episode represents a continuous period of accommodation or homelessness (in days).

Each episode may consist of numerous separate accommodation events.

Time homeless shown in bold.

Figure 1. Time homeless in relation to time in accommodation of the long-term homeless.

resettlement' model to take account of the very different needs of each (Pleace, 1995). For example, despite their obvious vulnerabilities, earlier attempts to register with different local authorities as in 'priority need' and their experience of several hostels over the years neither Russell nor Chris had been able to gain access to supported housing and indeed saw this as their priority. Yet by no means all favoured this kind of 'solution' to their homelessness with neither Bill or Don, for example, wanting any kind of permanent accommodation of their own. Instead, they talked of the need for a more extensive hostel network that would allow those who wished to travel to find accommodation when they wanted it but also not to have to rely upon night shelters and hostels that were under increasing pressure from young homeless people who neither saw as part of the same homeless 'community' (Deacon et al., 1995).

Still others challenged the assumption that it was in fact homelessness that was the defining feature, or 'problem', of their lives. Rather than the problem, the repeated episodes of rough sleeping that had punctuated his housing career were instead understood by Rob himself, for example, as a 'solution' to a broader set of problems relating not to housing but unemployment. Unable to find work and repeatedly dissatisfied with training schemes that offered little scope to develop his skills, Rob's solution to the boredom that characterised his day-to-day life was to take to the streets. There, as he constructed shelters or opened up squats, he was at least able to find work of his own; using a range of skills from brick laying and carpentry to an understanding of household plumbing that he had been unable to deploy in the formal labour market. Whilst such activities should not be confused with a desire to be homeless, of course, it might be suggested that for Rob his homelessness offered a kind of 'magical resolution' to problems relating less to his position in the housing than the labour market, with Rob leaving a number of private rented flats over the years in order to enjoy the 'work' that being homeless entailed (Hall \& Jefferson, 1976). 


\section{Reassessing Long-term Homelessness: The Episodically Homeless}

Whilst Rob's experiences warn against framing long-term homelessness as always and only a (housing and) 'welfare' issue, the biographies of a second set of respondents further complicate our understandings of the basic nature and shape of long-term homeless careers and of the dynamics driving those careers. Thus, the biographies of the majority of the men interviewed positioned them as neither the recently homeless-in-so-far as each had also been homeless prior to the current study-nor as the long-term homeless, in as much as each of these earlier homeless episodes had been of quite short duration and interspersed with much longer periods in accommodation of their own.

Despite almost half of this group being under the age of 25, nor does the shape of their biographies fit the model described by Hutson \& Liddiard (1991) in their examination of the housing and homeless careers of young homeless people. Rather than characterised by a series of distinct 'stages', with a steady decline in the use of independent accommodation over time, for the majority of this group their time both prior and subsequent to each homeless episode had been spent in accommodation of their own, most often in the private rented sector. Instead of a decline over time in the use of independent accommodation and a progression towards ever longer homeless episodes, for the majority of the 24 men making up this second group, their housing careers were therefore instead dominated by the use of private rented accommodation throughout, but interspersed by occasional and short-lived periods of homelessness.

The clearest way to illustrate these careers is to consider their basic shape as a function of time spent in accommodation and time homeless (Figure 2), fleshing this out with details gathered from individual biographies (Figure 3). Whilst such biographies complicate our understandings of long-term homelessness, with the majority of respondents becoming homeless for only short periods of time but on numerous occasions, they may also necessitate a re-appraisal of the traditional position of the private rented sector as a 'transitional' phase in people's housing careers or as some kind of 'youth' housing market (Jones, 1993; Pickvance \& Pickvance, 1994). Though almost half of the men in this group were under 25 years of age, a further 13 ranged in age between 26 and 56 years old, with the housing careers of these men too dominated by private rented housing, with a marked absence of other sectors (social housing, for example) and with none of the kind of progression over time into other tenures usually associated with the notion of a housing 'career' (Table 1).

Moreover, looking at those times at which each became homeless, of 77 separate homeless episodes no fewer than 36 followed the loss of accommodation in the private rented sector, with almost half of these addresses themselves of less than three months duration and a third including no kind of tenancy agreement. The suggestion is therefore that when reliant upon (insecure) private rented accommodation people often find themselves having to move, a supposition that is supported by the average duration of address for this group as a whole being just 0.8 years. It is at these points in an already unstable accommodation biography that people often become homeless, as they are unable to find an alternative place to live.

Yet it is not simply that the accommodation available to such people would seem to place them at considerable, and repeated, risk of becoming homeless 
but rather that their homelessness is often precipitated by attempts to resolve the difficulties that accompany living in this kind of accommodation. Thus, looking at the factors that precipitated each homeless episode, rather than the usual 'crisis' events identified in snap-shot surveys of hostel users (relationship break-up, problems with housing benefit or rent arrears, for example) the most common reason offered for losing accommodation was simply the attempt to find improved living conditions.

In a situation where the single most common reason (20 of 77) people gave for losing their accommodation related to 'wanting' to leave privately rented bedsits or flats it is clear we need to distinguish between what Jones (1993) describes as a 'decision' and a 'choice'. Here, Albert for example, describes the process by which he first found and then left the bedsit he lived in immediately prior to moving to the south coast and in to the first of two hostels:

[The flat I was in] was this tiny little bedsit [which I'd taken] just to get off the streets. There was no bedding, nothing. The Day Centre gave me some bedding. I used to go there for a shower, because there was no hot water where I was. There was a ... Belling cooker in there, and a bed-nothing else. You couldn't get nothing else in the room anyway. The place was terrible ... falling apart ... one of those places where a lot of drinking went on, noise and that... [One day] the council came down to measure the room and they said "this ain't fit for you to live in" [but they didn't re-house me because they had] nowhere for [me] to go, not for a single man ... In the end I just couldn't stick it any longer [and] I just got up one morning, packed me bits and pieces and just walked out ... that night I probably regretted it to be honest with you ... but I just got up that morning and I thought "I ain't having this place no longer" and I just left... And all I was doing more or less all day long was just walking around trying to get a bit of work. That was one of the reasons I came down here. (Albert, age 56, 4 December 1997)

Albert's account is not only about the kind of accommodation that the men interviewed here all too frequently described. It also concerns single homeless people's position in relation to a legislative framework that makes no provision for the housing of single people (unless found 'vulnerable') and the reliance of people caught in a position like Albert upon other forms of aid (day centres, for example) for what many would consider the basic necessities of life. But primarily it is an account concerning the experience of living in insecure and often appalling private rented accommodation whilst also being unemployed. As Richard makes clear, being unable to find work not only makes it harder to find a (decent) place to live it also adds significantly to the difficulties of trying to get by in housing like that described by Albert because "if you've got a job it's alright like, you can ignore where you're living but if you're living in a place all day long-well, it's no joke" (Richard, 24 December 1998).

Even whilst noting the dramatic increase in the proportion of the (long-term) unemployed amongst the single homeless population, it may therefore be that 


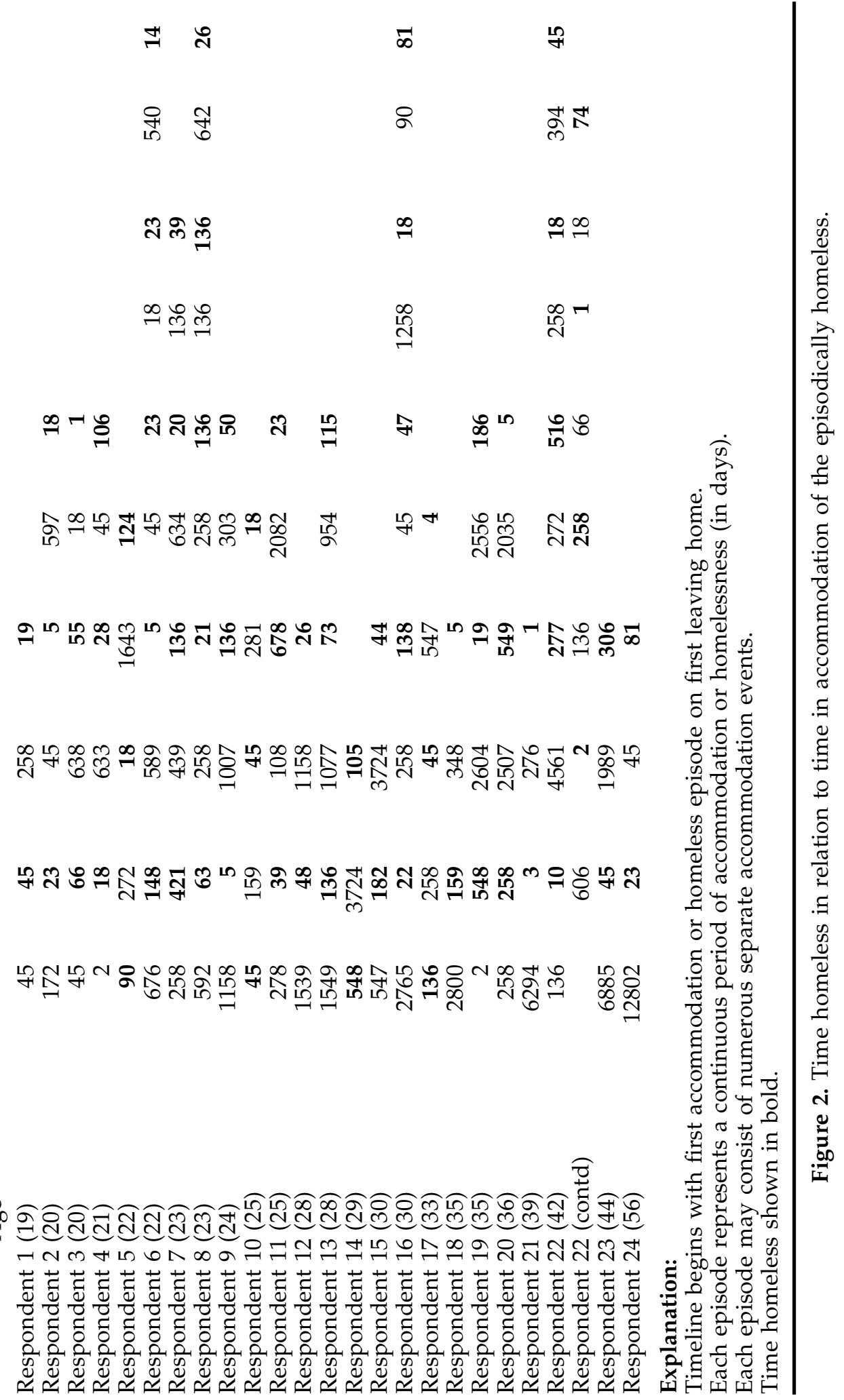


'Shaun' (age 22)

Brought up by his grandparents after his parents' divorce, Shaun left home at 16 unable to afford a flat of his own. After a period in two bed and breakfast 'hotels' he moved in with friends before being able to get enough money to secure a deposit on his own bedsit. At the end of the tenancy the landlord offered him a place in another bed and breakfast for a few weeks until Shaun was able to move into a new flat owned by the same landlord. Over the next few years Shaun moved through seven bedsits and flats, sometimes living on his own and sometimes with his girlfriend and interspersed by the occasional stay at his girlfriend's parents or with friends. With neither of them able to find any work, Shaun and his girlfriend eventually decided to move to the south of England, stopping on the way in London where Shaun had relatives. Reaching the coast they again found a private rented flat which they shared until their relationship ended and Shaun moved out. Still unemployed, for the next couple of months Shaun moved between different friends before finally running out of places to stay and, after a night on the street, came to the hostel where he was interviewed.

'Simon' (age 22)

Simon's housing career has been more chequered. Again, leaving home at 16, Simon's first flat was provided by social services. After six months Simon grew lonely and moved in with his father for a little over a year before moving away from the town in which he grew up in order to try and find work. There followed a period of some four months of moving between hostels and rough sleeping in different towns before Simon moved back to his home town and into a series of four private rented flats, staying for about six months in each. Still unable to find work Simon then moved away again, this time to take up a government training placement in a local resort. Sacked after only a few weeks Simon returned to his home town, this time staying in a local hostel for a few nights before being offered move-on accommodation in the form of a private rented bedsit. Leaving again after a few weeks, and again to try and find work, Simon moved further down the coast to another resort where after a few nights sleeping rough and a couple of weeks in a bed and breakfast hotel he was able to find work that included live-in accommodation. Keeping the job for only three weeks, Simon decided to try and look for work in London where again he had first to sleep rough before gaining a place in a hostel and then sharing a room above a local bar rented from a landlord claiming Housing Benefit for self-contained bedsits but providing only shared accommodation. Following an argument with the landlord Simon again found himself homeless and, still out of work, moved back to the south coast where another week sleeping rough and two nights at the night shelter bought him to the hostel where he was interviewed.

\section{'Andy' (age 35)}

Andy did not leave home until he was 26, when he moved into a two-bedroom privately rented flat with his wife. For the next seven years Andy worked in a series of businesses run by either his own or his wife's family. When their marriage broke up Andy moved in with his brother but, keen not to outstay his welcome, quickly moved on to other relatives. As the strain with both his own and his wife's family grew, Andy ceased working in the family business and decided to move to a new area of London. Following a few months in a large hostel he then moved down to the south coast in the hope of finding both somewhere to live and employment, having worked in the town some years earlier. Staying first with one of the friends from the hostel with whom he had moved and who had gained a local authority placement in the town, Andy and another friend quickly found a bedsit each in the same building although neither was able to find work. But they stayed there for only a few weeks before moving twice again, the last time so that Andy could share with a new partner. When this relationship ended Andy again found himself both unemployed and homeless and, rather than moving back to his family, approached the hostel where he was interviewed.

Figure 3. Homeless and housing careers of the episodically homeless. 
Table 1. Accommodation used by episodically homeless as percentage of time in accommodation since first leaving home (excluding time homeless)

\begin{tabular}{lr}
\hline Private rented accommodation & $\mathbf{4 7}$ \\
Local authority/housing association & $16 \%$ \\
Friends & $8 \%$ \\
Relatives & $8 \%$ \\
Tied accommodation & $7 \%$ \\
Prison & $7 \%$ \\
Squats & $2 \%$ \\
Owner occupied & $1 \%$ \\
Other & $3 \%$ \\
Independent accommodation & $\mathbf{7 6} \%$ \\
Secure independent accommodation (accommodation with & $\mathbf{3 6 \%}$ \\
tenancy or mortgage agreement in respondent's own name) & \\
Average duration of each address & $\mathbf{0 . 8}$ years \\
\hline
\end{tabular}

Note: (Percentages may not add up to $100 \%$ due to rounding).

previous studies have under-estimated the importance of the connections between homelessness and unemployment or have at least failed to unpack those connections in sufficient detail. Certainly, with only three of the 24 respondents in this group reporting any kind of drug, alcohol or mental health problems, one of the most striking things about these men is the almost total lack of any additional vulnerabilities that might otherwise help explain their frequent returns to homelessness. Rather, the most obvious and striking characteristic tying each of these biographies together is a story of long-term and chronic unemployment that severely limited people's housing options. Indeed, half of the menwith 11 of these being under the age of 25-had never had any kind of (formal) paid employment, whilst all of the others had either become homeless since last working (an average period of five years) or had been homeless at periods in the past when they were also out of work.

Rather than seeking to explain the homeless careers described here in relation to either and only a person's access to accommodation (that is, in relation to the structure of the housing market) or their employment biographies, such careers therefore need exploring in relation to the dynamics operating between housing and labour markets that place people in a position of multiple structural disadvantage. Indeed, and not surprisingly, following those who simply wished to look for a better place to live, the next most frequent reasons for leaving the accommodation immediately preceding a homeless episode were directly related to the experience of unemployment: either when a person lost their job (seven times); because they moved in order to try and find work somewhere else (four times); or because job loss preceded, and added to, some other crisis that served as the main precipitating factor in the loss of their accommodation, for example problems of rent arrears or the break-up of a relationship.

More significantly, perhaps, in only one of 77 homeless episodes experienced by this group did a person become homeless whilst in employment, and only then to lose their job soon afterwards. In other words, it is not simply that recent years have seen an increasing proportion of the unemployed rather than the low paid or insecurely employed making up the single homeless population (Greve, 
1997). Rather, it is that the experience of homelessness can no longer be considered apart from the problems of unemployment and might to some considerable degree be something only experienced by those outside the labour market, either by virtue of unemployment, sickness or disability.

Another possibility is to explore the dynamics of homelessness in relation not to housing or labour markets but those informal means of accommodation and support that people often turn to in times of housing need and which prevent people from presenting as visibly homeless, most obviously the support of friends and especially relatives. As Jones (1993) has argued, a person's access to these kinds of informal networks should not be confused with a person's individual characteristics. Rather, the types of family background that often lead to a person leaving home prematurely (and perhaps without a place to go) and restricts any subsequent access to accommodation and support from family members, themselves show remarkable structural similarities regarding parental unemployment, family poverty, or existing housing stress. Even in the absence of a history of overt family conflict or abuse, such situations therefore often make it difficult for people to turn to their families in times of housing need.

But whilst such explanations are clearly of some use in helping to explain the more limited housing options facing many young people-and seven of the 12 young people interviewed here also reported either leaving home following severe family conflict or such conflict arising on the (only) attempt they made to return to the 'parental' home-we should also not allow them to over-determine our explanations of homelessness. The use of friends' accommodation in particular, for example, was a common feature of many of these men's housing 'careers' with a (smaller) number also turning to relatives in times of crisis. Indeed, Table 2 would suggest that 'hidden homelessness' is by no means a dominant feature only of the housing careers of homeless women (Watson \& Austerberry, 1986). Considering people's use of temporary accommodation it is clear that the episodically homeless at least are in fact more likely to turn to friends (and to a lesser extent relatives) than they are to night shelters or hostels in times of severe housing stress, with some 25 per cent of this group never having turned to hostel accommodation prior to the time of study and despite previous experiences of rough sleeping.

That people did not always turn to these networks, or that it was often not possible to stay with friends and relatives for long, should not necessarily be seen as a sign of family 'dysfunction' or of more general social isolation. Rather, in the case of friends people reported the difficulties experienced staying with friends whose own housing circumstances were often very similar to their own. In other cases it became evident that it was not so much that people were unable to turn to relatives because of some kind of family conflict but that (in the case of the older respondents in particular) such networks were either simply unavailable or people who had been living independently for years simply did not want to have rely (again) on family (or friends) to help resolve their housing difficulties, as Andy's account illustrates (Figure 3).

Finally, whilst Table 2 describes a less prominent role for night shelters and hostels in the homeless careers of these men than might be expected from traditional accounts of the 'long-term' or repeatedly homeless, their experiences of homelessness might also be of some importance to current debates concerning the role of hostels in intervening in the homeless dynamic (Neale, 1995). Most significantly, examining the accommodation most frequently found following a 
Table 2. Frequency of accommodation use by type in homeless episodes by episodically homeless

\begin{tabular}{lr} 
Friends & 64 \\
Relatives & 24 \\
Hostel/night shelter & 59 \\
Rough sleeping & 59 \\
Bed and breakfast & 41 \\
Number of accommodation events & 247 \\
Number of homeless episodes & 77 \\
\hline Note: (Figures include accommodation used at time of \\
interview.
\end{tabular}

rough sleeping event and that subsequent to a stay in a night shelter or hostel reveals the limited role that hostels currently play in interrupting that dynamic. Although for this group a night shelter or hostel represented the most common form of accommodation following a period sleeping rough (accounting for 24 of the 59 places of accommodation used immediately following a rough sleeping event) those same hostels were clearly far less successful in interrupting these men's homeless careers in the longer term. Thus, of the 38 hostel stays recorded by this group (excluding that used at the time of study) in only 15 cases did a person leave a night shelter or hostel to move directly in to their own accommodation. Further, in all but one of these cases this accommodation was found in the private rented sector, from which each was to become homeless again at some later point in their biography (with a third of these cases following the loss of that same privately rented bed sit of flat) (Table 3).

The implication is that as these men's homeless careers can be understood as the result of the intersections of (long-term) unemployment and their reliance upon an (often insecure) private rented housing market, intervention strategies that rely simply upon helping people to gain entry back in to that market at those times they present as visibly homeless will do little to challenge the long-term dynamics of episodic homelessness. Yet this is not an argument for the usual 'housing plus' solution, at least as proposed by those who would point to the additional 'welfare' needs of the single homeless. With few of this group articulating any kind of additional vulnerabilities, rather than some kind of supported accommodation, the primary requirement of these men is simply improved and more secure affordable rented housing (whether in the social registered or a more tightly regulated private rented sector) and employment.

\section{The First Time Homeless}

Whilst the biographies explored above suggest a series of important differences between the experiences of long-term and episodic homelessness, a question still remains as to the nature of any possible relationships between the two. By its nature, a biographical approach remains right hand justified such that it is not possible to know whether the careers described in the preceding section may in the future develop into long-term homelessness or whether those who have a history of long-term homelessness will at some point in the future be able to retain accommodation. At the same time, differences are clearly apparent 
Table 3. Accommodation used immediately following a rough sleeping event or hostel stay by episodically homeless

Accommodation used immediately following a rough sleeping event

Hostel/night shelter

24

Friends

Bed and breakfast

Relatives

Rough sleeping

Squat

Private rental

Owner occupied

Total rough sleeping events

(Explanation: where a person moves location within the same rough sleeping episode each place of rough sleeping is calculated as a separate rough sleeping event.)

Accommodation used immediately following a stay in night shelter or hostel

Private rental

14

Hostel/night shelter

10

Rough sleeping

Friends

Social registered housing

Bed and breakfast

Other

Total hostel stays

8

Note: Figures exclude accommodation used at time of interview.

between the shape of either group's careers to the time of interview, and between the dynamics driving those careers; most obviously, the higher level of individual vulnerabilities found amongst the long-term homeless.

But a question remains as to any such differences between those who at the time of interview were visibly homeless for the first time-some 11 people in all-and those who had also been homeless in the past. Where this last group differed amongst themselves more than was the case with either of the other two groups, but also shared a number of the characteristics of people in either of those groups, they point to the importance of not discounting the role of individual histories and actions in our explanations of the homeless dynamic.

For example, ranging in age from between 26 and 51 years old, in contrast to those who had been repeatedly homeless but in common with the long-term homeless a number of this group had serious vulnerabilities, with four of the 11 having a serious drug addiction and a further two problems of mental health. Similarly, although one of the clearest ways in which five of these men differed from all of the other respondents was that they had, until recently, spent their whole lives in work, four had never been able to find employment and another, although working early on in his adult life, had been unemployed for the last eight years. The answer to differing experiences of homelessness would therefore seem to lie in the ways in which, even whilst a combination of certain factors may over-determine the likelihood of a person becoming homeless, these factors also always come together in different ways for different individuals and with different outcomes (Jones, 1993). 
For example, for three of the respondents (each of whom had been in employment the whole of their adult lives) homelessness had simply followed the onset of their first experience of unemployment whilst also living in private rented or tied accommodation. But for others their homelessness was the result of a further combination of factors. Whilst George (in his late twenties) had a serious heroin addiction and Martin (in his mid-thirties) had suffered a series of mental health related problems throughout his adult life, for example, neither became homeless until such point as these problems worsened and precipitated a loss of employment. Likewise, whilst neither Terry, Craig or John-in their mid-twenties and early thirties respectively-had ever worked, and Paul had not worked for the last eight years, all four had spent most of their lives living with relatives and became homeless only at such a point as these support networks 'ran out'; either because they moved away from home in an effort to find work or because of family conflict. At the same time, differences are apparent between the broader housing histories of this group and the other respondents. Most notably, aside from the higher proportion of time spent living with relatives since first leaving home, some 30 per cent of these people's time since first leaving home had been spent in social registered housing, more time in fact than had been spent in the private rented sector (at 27 per cent).

More importantly, and even without being able to look beyond the time of interview, one of the advantages of a biographical approach is precisely that it allows one to look at patterns of accommodation use following earlier periods of homelessness. One of the more striking things to emerge in an examination of the housing careers of the episodically homeless was how quickly once a person became both unemployed and restricted in their housing choices to a reliance upon poorer quality private rented accommodation they became homeless again. Though each of the men in this final group of respondents were in their first homeless episode at the time of interview it is therefore quite possible that this episode will be followed by future episodes, particularly if they are unable to find work and have to turn to private rented accommodation in order to find housing (as would seem likely in a context of continued restrictions on access to social registered housing for single people and the growing use of the private rented sector by those seeking to house the homeless) (Rugg, 1997).

\section{Conclusions}

Studies of homelessness have been slow to utilise the kind of biographical approaches increasingly used in other fields. Despite the obvious difficulties in constructing these biographies, this paper has demonstrated that it is in fact possible to construct detailed biographies with homeless people that describe not only their housing careers but also their experiences in other arenas. A biographical approach gives space to a fuller examination of the complex ways in which people negotiate the opportunities and constraints shaping their access to housing, employment and welfare, and allows for a consideration of the ways in which such negotiations are themselves shaped by a person's individual circumstances, characteristics, vulnerabilities and experiences. Such biographies may also represent the most appropriate method for unpacking the more sophisticated explanations of homelessness that have emerged in recent years.

Certainly a biographical approach is likely to be of some considerable use in developing our understanding of homelessness in a number of ways. For 
example, detailed accommodation biographies can be used to clarify the ways in which people find their way around an accommodation and service network or to examine the kinds of accommodation to which people turn when they become homeless. In so far as they give a far clearer picture of the relative duration and form of a person's homelessness, they might also be used to further unpack our understanding of the experience of homelessness and to better place homeless people's own understandings of concepts such as 'home' and 'homeless' in the perspective of their lives as a whole (May, forthcoming).

Here, they have been used at a broader level of analysis to consider questions relating to homeless careers. Earlier studies examining the nature and shape of homeless careers have worked with only schematic or truncated housing histories. They have provided an inaccurate picture of the basic nature and shape of those careers and misrepresented their essential dynamics. Where such studies have drawn a clear distinction between the more recently and long-term homeless, and presented homelessness as progressive, the more detailed biographies analysed here describe a more complex picture.

Although not necessarily representative of other single homeless people, the truly long-term homeless made up only a small proportion of those interviewed. For these men homelessness had indeed been a relatively long-term experience. But there is little evidence to suggest that their homeless careers had been progressive in any clear or simple sense. Rather, whilst for some homelessness had been an almost permanent experience, for others periods on the street or in hostels that had often lasted years were interspersed with equally long periods in their own accommodation. Further, although some of these men talked of a desire for the kind of supported housing schemes that are often advanced as a solution to those who have been homeless for a long time, and who may also have significant and multiple vulnerabilities, by no means all embraced these schemes as an answer to their housing needs. A key advantage of a biographical approach is therefore that it can enable a clearer understanding to emerge of different people's experiences and desires, recognising the individuality of homeless people and thus the need for a variety of responses to the problems of homelessness without denying the structural similarities that lie behind (long-term) homelessness.

The study also revealed a significant proportion of men who were visibly homeless for the first time. Although these men differed from each other in a number of ways, drawing them together was either a stable and continuous employment history, the end of which had preceded their homelessness or, if unemployed, the extensive support of relatives with their homelessness beginning only when that support ran out.

But the majority of men interviewed fitted within a definition of neither the long-term nor more recently homeless. Rather, even though each episode was often of quite short duration, these men had been homeless on numerous occasions, with these occasions sometimes separated by up to several years. In the intervening period their accommodation biographies showed none of the progression usually associated with the concepts of either a housing or homeless 'career' but were instead almost entirely dominated by poor quality, often insecure private rented accommodation.

Almost half of these men had also never been in work with the others all long-term unemployed. Even whilst noting the increasing numbers of long-term unemployed amongst the single homeless hostel population, the housing and 
employment biographies of these men therefore suggest that it is possible we have failed to recognise the full significance of unemployment in the homeless dynamic. Inexplicable in terms of individual vulnerabilities, the repeated experiences of homelessness that characterised these men's lives has been explained as the result of a position of multiple structural disadvantage relating to their experiences in relation to both the housing and labour markets and a legislative framework that denies more secure forms of housing to most poorer single people. Whilst by its nature a biographical approach focuses upon the always unique experiences of the individual, it is this shared position of multiple structural disadvantage that may differentiate the peculiar and unique nature of the social exclusion of a significant proportion of the single homeless population and that sets these men's experiences apart from the experiences of both the housed population in general and other poor or unemployed people (Jones, 1997; Pleace, 1998).

In so far as the study was conducted only with those currently homeless, the biographies analysed here cannot tell us about those people for whom intervention in the form of hostel accommodation, move-on assistance or supported housing schemes has been successful. But it is clear that for these men, almost all of whom had some prior experience of hostel use, no such interventions had stopped them from becoming homeless again but had instead arrested their homelessness only in the short term. More permanent solutions to homelessness may therefore only lie with the kind of multi-dimensional strategies now being explored with young homeless people and, most obviously, the kind of accommodation and employment schemes to be found in the Foyer projects (Quilgars \& Anderson, 1997). Whilst not wishing to detract from the particular difficulties experienced by young homeless people (and it is notable, for example, that in the current study of those who had never worked almost all were under the age of 25) it should also not be forgotten that as here the majority of single homeless hostel residents are in fact over 25 years of age. Where these peoples' homelessness seemed to emerge from a similar dynamic as that found amongst the younger respondents, it might therefore be necessary to expand such schemes.

In the longer term, however, the results of the current study clearly support those who would see a solution to homelessness as lying only with improved access to both employment and secure and affordable housing. Such housing is most likely to be found in the social registered sector. One indication of the ability of that sector to help stabilise a person's housing career may be found by comparing the average length of stay in the private rented and social registered sectors amongst these respondents as a whole. Where the former equated to an average of just 1.07 years the latter averaged at a little over four years. Given the role that insecure and poor quality private rented accommodation has played in the return to homelessness of so many of the men interviewed care should certainly be taken before embracing the ability of the private rented sector to offer a solution to the housing needs of single homeless people. Whilst it may prove possible to improve the quality and security of accommodation in that sector, recent initiatives in this direction have found it extremely hard to do whilst also maintaining access to private rented housing for those on lower incomes or benefits and suggesting it may be time to (re)turn to other solutions to the problems of homelessness. 


\title{
Correspondence
}

\author{
Dr Jon May, Department of Geography, Queen Mary and Westfield College, \\ University of London, Mile End Road, London E1 4NS, UK.
}

\section{Notes}

1. These latter interviews were also important in so far as they allowed people to explore their biographies in ways other than as a story relating only to homelessness (the 'framing' mechanism of the study) (see Rosenthal, 1993). For example, in the case of Richard, who had been homeless not once but on numerous occasions and including extensive periods when he had slept in his car, the interview quickly moved away from the problems he had experienced over the years in not only finding but retaining accommodation to a discussion of his difficulties in finding work. Thus it emerged that it was his sense of failure in finding employment that most clearly structured Richard's sense of himself and helped make sense of his accommodation biography, which tended to shift in line with his attempts to find work. This shift towards a life history approach is therefore of more than only methodological importance. Whilst Richard's narrative worked to disrupt too easy an interpretation of his homeless career, where each interview moved beyond a consideration of only those periods at which a person had been homeless to include a (schematic) account of their whole lives, the interviews therefore worked to reclaim an identity for each respondent beyond only their identity as a 'homeless person'. Whilst this process may in itself be important to a more sensitive understanding of the appropriate form of any subsequent intervention strategy (see below) it may also be one of the reasons people actually enjoyed doing the interviews. The interview process gave people an opportunity to talk about themselves in their own terms rather than being already defined as having experiences that were only valid so long as they related to homelessness (Carlen, 1996).

2. In the following analysis homelessness is defined as any consecutive period of rough sleeping or time spent in a night shelter, hostel or bed and breakfast hotel (whilst also claiming benefits). In line with those who would define homelessness along a continuum of housing need, including patterns of 'hidden homelessness', a homeless episode is also taken as including accommodation with friends or relatives where that accommodation was of less than two months duration (and excluding returns to the parental home). A two-month limit on this kind of accommodation was imposed so as to include only those stays that might more obviously represent a temporary or emergency arrangement. An exit from homelessness is defined as any time in independent accommodation irrespective of security of tenure (therefore including accommodation such as squats or periods spent as part of a travelling community) or accommodation with friends or relatives of more than two months duration. An exit is also defined as including other forms of institutional accommodation such as hospitals or prisons (Pavialin et al., 1993, 1996).

\section{References}

Adams, B. (1990) Time and Social Theory (Cambridge, Polity).

Akiyu, F. (1992) Multi-method approach to the study of homelessness, in: P. Kennett (Ed.) New Approaches to Homelessness, pp. 62-73 (Bristol, SAUS, University of Bristol).

Anderson, I., Kemp, P. \& Quilgars, D. (1993) Single Homeless People (London, HMSO).

Barclay, C. (1986) Schematization of autobiographical memory, in: D. Rubin (Ed.) Autobiographical Memory, pp. 82-99 (Cambridge, Cambridge University Press).

Bines, W. (1994) The Health of Single Homeless People (York, Centre for Housing Policy, University of York).

Brandon, D. et al. (1980) The Survivors: A Study of Homeless Young Newcomers to London and the Responses Made to Them (London, Routledge and Kegan Paul).

Campanelli, P. \& Thomas, R. (1994) Working Lives Developmental Research: Issues Surrounding the Collection of Life-time Work Histories (London, Department of Environment/Joint Centre for Survey Methods).

Carlen, P. (1996) Jigsaw: A Political Criminology of Youth Homelessness (London, Routledge).

Chamberlayne, P. \& King, A. (1993) Analysing biographical narrative interviews: a comparative experience.

Paper presented to British Sociology Association Conference, Colchester, April.

Conover, S., Berkman, A., Gheith, A., Jahiel, R., Stanley, D., Geller, P., Valencia, J. \& Susser, E. (1997) 
Methods for successful follow-up of elusive urban populations:an ethnographic approach with homeless men, Bulletin of the New York Academy of Medicine, 74(1), pp. 90-108.

Daly, G. (1996) Homeless: Policies, Strategies and Lives on the Streets (London, Routledge).

Deacon, A., Vincent, J. \& Walker, R. (1995) Whose choice, hostels or homes? Policies for single homeless people, Housing Studies, 10(3), pp. 345-363.

Evert, D. \& Oscarberman, M. (1995) Alcohol related cognitive impairments: an overview of how alcoholism may affect the workings of the brain, Alcohol Health and Research World, 19(2), pp. 89-96.

Farr, R., Koegal, P. \& Burnam, A. (1986) A Study of Homelessness and Mental Illness in the Skid Row area of Los Angeles (Los Angeles, Los Angeles County Department of Mental Health).

Forest, R. \& Murie, A. (1991) Housing markets, labour markets and housing histories, in: J. Allen \& C. Hamnett (Eds) Housing and Labour Markets: Building the Connections (London, Unwin Hyman).

Greve, J. (1997) Preface: homelessness then and now, in: R. Burrows, N. Pleace \& D. Quilgars (Eds) Homelessness and Social Policy, pp. xi-xvii (London, Routledge).

Halfacree, K. \& Boyle, P. (1993) The challenge facing migration research: the case for a biographical approach, Progress in Human Geography, 17(3), pp. 333-348.

Hall, S. \& Jefferson, T. (Eds) (1976) Resistance through Ritual: Youth Sub-cultures in Post-war Britain (London, Hutchinson).

Hutson, S. \& Liddiard, M. (1991) Young and homeless in Wales: government policies, insecure accommodation and agency support. Occasional Paper No. 26 (Swansea, University College Swansea).

Hutson, S. \& Liddiard, M. (1994) Youth Homelessness: The Construction of a Social Issue (London, Macmillan).

Jarvis, H. (1997) Negotiating the city through gender divisions of labour: household biographies from London and Manchester. Paper presented at the Royal Geographical Society/Institute of British Geographers Annual Conference, University of Exeter, January.

Jones, G. (1993) On the margins of the housing market. Working Paper No. 3, Young People In and Out of the Housing Market (Scotland, Scottish Council for Single Homeless).

Jones, G. (1997) Youth homelessness and the underclass, in: R. MacDonald (Ed.) Youth, the Underclass and Social Exclusion, pp. 96-112 (London, Routledge).

Jones, G. \& Stevens, C. (1993) Researching young people in and out of the housing market. Working Paper No. 5, Young People In and Out of the Housing Market (Scotland, Scottish Council for Single Homeless).

Liddiard, M. (1992) Explaining youth homelessness: issues and approaches, in: P. Kennett (Ed.) New Approaches to Homelessness (Bristol, SAUS, University of Bristol).

Martin, J. \& Roberts, C. (1984) Women and Employment: A Lifetime Perspective (London, Department of Environment, HMSO).

May, J. (forthcoming) Of 'nomads' and 'vagrants': single homelessness and narratives of home as place, Environment and Planning D: Society and Space.

Mayer, K. \& Tuma, N. (Eds) (1987) Application of Event History Analysis in Life Course Research (Berlin, Max-Planck Institute).

Murie, A. \& Jeffers, S. (1987) Living in bed and breakfast. Working Paper 71 (Bristol, SAUS).

Neale, J. (1995) The role of supported hostel accommodation in meeting the needs of single homeless people. DPhil thesis, University of York.

Neale, J. (1997) Homelessness and theory reconsidered, Housing Studies, 12(1), pp. 47-61.

Pavialin, M., Sosin, M., Westerfelt. \& Matsueda, R. (1993) The duration of homeless careers: an exploratory study, Social Service Review, 67(4), pp. 576-598.

Pavialin, M., Wright, B., Mare, R. \& Westerfelt, A. (1996) Exits from and returns to homelessness, Social Service Review, (December), pp. 33-57.

Pickvance, C. \& Pickvance, K. (1994) Towards a strategic approach to housing behaviour: a study of young people's housing strategies in south-east England, Sociology, 28(3), pp. 657-677.

Pleace, N. (1995) Housing Vulnerable Single Homeless People (York, Centre for Housing Policy, University of York).

Pleace, N. (1998) Single homelessness as social exclusion: the unique and the extreme, Social Policy and Administration, 32(1), pp. 46-59.

Pleace, N., Burrows, R. \& Quilgars, D. (1997) Homelessness in contemporary Britain: conceptualisation and measurement, in: R. Burrows, N. Pleace \& D. Quilgars (Eds) Homelessness and Social Policy, pp. 1-18 (London, Routledge).

Quilgars, D. \& Anderson, I. (1997) Addressing the problem of youth homelessness and unemployment: the contribution of Foyers, in: R. Burrows, N. Pleace \& D. Quilgars (Eds) Homelessness and Social Policy, pp. 216-228 (London, Routledge). 
Randall, G. (1988) No Way Home: Homeless Young People in Central London (London, Centrepoint Soho).

Randall, G. (1992) Counted Out: An Investigation into the Extent of Single Homelessness Outside of London (London, CRISIS).

Rosenthal, G. (1993) Reconstruction of life stories: principles of selection in generating stories for narrative biographical interviews. Paper presented to British Sociology Association Conference, Colchester, April.

Rossi, P. (1989) Down and Out in America: The Origins of Homelessness (Chicago, Chicago University Press).

Rubin, D. (Ed.) (1986) Autobiographical Memory (Cambridge, Cambridge University Press).

Rugg, J. (1997) Opening doors in the private rented sector: developments in assistance with access, in: R. Burrows, N. Pleace \& D. Quilgars (Eds) Homelessness and Social Policy, pp. 172-188 (London, Routledge).

Shaw, M. (1998) A place apart: the spatial polarisation of mortality in Brighton. Draft manuscript (Bristol, Department of Geography, University of Bristol).

Sosin, M., Piliavin, M. \& Westerfelt, H. (1990) Towards a longituidinal analysis of homelessness, Journal of Social Issues, 46(4), pp. 157-174.

Tomas, A. \& Dittmar, H. (1995) The experience of homeless women: an exploration of housing histories and the meaning of home, Housing Studies, 10(4), pp. 493-515.

Tonkin, E. (1995) Narrating our Past: The Social Construction of Oral History (Cambridge, Cambridge University Press).

Vincent, J., Deacon, A. \& Walker, R. (1995) Single Homeless Men: Roads to Resettlement? (Aldershot, Averbury).

Watson, S. \& Austerberry, H. (1986) Housing and Homelessness: A Feminist Perspective (London, Routledge and Kegan Paul).

Whynes, D. (1991) Mobility and single homelessness, Area, 23(2), pp. 111-118. 